\title{
Os direitos humanos no ensino de Psicologia: entre ciência e compromisso político
}

\section{- Human Rights in Psychology Education: between science and political commitment}

\section{Ari Fernando Maia'}

Resumo: $\mathrm{O}$ artigo discute a necessária articulação, na formação em Psicologia, entre os ideais de fazer prático, científico e o compromisso ético-político, tomando como ponto de partida a contradição expressa no progresso do esclarecimento: todo objeto da cultura e da ciência também contém elementos de barbárie. A formação em Psicologia é destacada porque a grande diversidade de matrizes epistemológicas que a compõe não impediu que a categoria estabelecesse um compromisso por consubstanciar direitos humanos na atuação profissional, reconhecendo o potencial de barbárie da aplicação da ciência psicológica. Procura-se identificar em que sentidos os direitos humanos foram lidos pela categoria dos psicólogos e como isso pode se refletir em estratégias para lidar com as contradições da ciência psicológica em um momento de crise dos valores relacionados aos direitos humanos e à formação.

Palavras-chave: Educação em direitos humanos. Formação em Psicologia. Teoria Crítica.

Abstract: The article discuss the necessary articulation, in Psychology education, between different ideals of practical, scientific and ethical-political commitment, taking as a starting point the contradiction expressed in the

1 Doutorado em Psicologia Escolar e do Desenvolvimento Humano pela Universidade de São Paulo (USP). Professor Universidade Estadual Paulista, Faculdade de Ciências da Unesp, campus de Bauru-SP e do Programa de pós-Graduação em Educação Escolar da Faculdade de Ciências e Letras da Unesp, campus de Araraquara-SP. ari.maia@ unesp.br 
progress of enlightment: every object of culture and science also contains barbaric elements. Psychology training is highlighted because the great diversity of epistemological matrices did not prevent the category from establishing a commitment to consolidate human rights in professional practice, recognizing the barbaric potential of the application of psychological science. It seeks to identify in which senses human rights were read by the category of psychologists and how this can be reflected in strategies to deal with the contradictions of psychological science in a time of crisis of values related to human rights and training.

Keywords: Human rights education. Psychology education. Critical Theory.

\section{Psicologia: ciência, profissão e ideais éticos}

Para a discussão que pretendemos fomentar nesse artigo será utilizada uma definição operacional, ad hoc, para a Psicologia, como um vasto campo de teorias, técnicas e práticas aplicadas a vários objetos que gravitam ao redor das noções de individualidade, subjetividade privada, mente ou comportamento. Tomaremos as teorias como modelos que procuram descrever a subjetividade humana e explicar como operam suas funções principais, como o pensamento, a linguagem, a memória, a percepção, a conduta etc. As técnicas abarcam o conjunto de ferramentas desenvolvidas pelos pesquisadores e profissionais de psicologia para observar, mensurar e interferir sobre os fenômenos psicológicos. Finalmente, as práticas constituem formas de atuação desses profissionais que se consolidaram historicamente, como a clínica, a psicologia escolar ou organizacional etc., orientadas pelas teorias e por ideais éticos. Quando nos referirmos à Psicologia, portanto, será sempre abarcando seu desenvolvimento teórico, as inúmeras ferramentas que foram desenvolvidas e se aplicam em contextos objetivos determinados e os ideais éticos que dirigem a atuação.

A principal questão que será discutida nesse artigo, sobre a formação de psicólogos e a apreensão dessas teorias, técnicas e práticas, diz respeito à dimensão ético-política da formação, ou seja, para que fins são formados os psicólogos e em que medida eles podem compreender os fins imanentes às teorias, técnicas e práticas que aprendem durante a formação. Entendemos que, como todo conhecimento e ciência humanos, a Psicologia compartilha a contradição apontada de forma aguda por W. Benjamin: "nunca houve um monumento da cultura que não fosse também um monumento da barbárie" (BENJAMIN, 1994, p. 225). Também a famosa fórmula da Dialética do Esclareci- 
mento: "do mesmo modo que os mitos já levam a cabo o esclarecimento, assim também o esclarecimento fica cada vez mais enredado, a cada passo que dá, na mitologia" (HORKHEIMER; ADORNO, 1985, p. 26) trata dessa contradição.

Em suma, a pretensão das ciências, expressa no ideal de dominação da natureza, resulta no uso indiscriminado do saber para exercício do poder sem limites, e tem em episódios históricos cruciais, como Auschwitz e as bombas atômicas lançadas sobre Hiroshima e Nagasaki, seus momentos mais conspícuos, mas se manifesta igualmente em fenômenos de longa duração como o colonialismo e a escravização. Essa constatação histórica não induz a Teoria Crítica da Sociedade a nenhum niilismo, mas ao imperativo ético de realizar a autocrítica da ciência em sua relação com o poder. Trata-se de pensar radicalmente as contradições da razão iluminista: "se o esclarecimento não acolhe dentro de si a reflexão sobre esse elemento regressivo, ele está selando seu próprio destino" (HORKHEIMER; ADORNO, 1985, p. 13). Se o elemento regressivo do conhecimento é esquecido, a contínua reprodução da barbárie por meio do saber não encontrará termo e seguiremos cegamente rumo à autodestruição. O imperativo ético de que Auschwitz não se repita (ADORNO, 2000), o primeiro de todos para a educação, implica lidar com essas contradições durante a formação dos profissionais psicólogos.

Não é difícil encontrar exemplos desse entrelaçamento entre razão e irracionalidade, entre ciência e barbárie, nas ciências psicológicas. Não é mera coincidência, que no processo da Revolução Francesa, o médico Phillipe Pinel tenha reivindicado para os chamados loucos a instituição psiquiátrica ao invés da prisão na Bastilha e que ela, uma vez consolidada como enclave do irracional patológico em meio a uma sociedade pretensamente bem ordenada, se convertesse em modelo de exclusão, encarceramento e morte, com exemplos particularmente bárbaros no Brasil (Arbex, 2013). Segundo Foucault (1984) é a partir de meados do século XVII que procedimentos de exclusão da loucura se disseminam. Em suas palavras:

Criam-se (e isso em toda a Europa) estabelecimentos para internação que não são simplesmente destinados a receber os loucos, mas toda uma série de indivíduos bastante diferentes uns dos outros, pelo menos segundo nossos critérios de percepção: encerram-se os inválidos pobres, os velhos na miséria, os mendigos, os desempregados opiniáticos, os portadores de doenças venéreas, libertinos de toda espécie, pessoas a quem a família ou o poder real querem evitar um castigo público, pais de família dissipadores, eclesiásticos em infração, em resumo todos aqueles que, em relação à ordem da razão, da moral e da sociedade, dão mostras de "alteração" (p. 78).

Mais que exercer uma vocação curativa, as funções primordiais dessas instituições são: segregar os representantes de uma razão dissidente e impor aos demais uma lógica, uma ratio, que os impele ao trabalho e à acumulação. 
A sociedade burguesa emergente não tolera manifestações alternativas do que ela admite como racional. Novamente, Foucault (1984) revela o entrelaçamento entre saber e poder de forma magistral:"o internamento que o louco [...] recebe na época clássica não põe em questão as relações da loucura com a doença, mas as relações da sociedade consigo própria" (p. 79). Efetivamente, a loucura opera como episteme, impondo aos que são considerados não loucos o peso da racionalidade da produção incessante, cumulativa e infinita de riquezas em uma ordem social necessariamente excludente e autodestrutiva. O entrelaçamento entre ciência e barbárie na Psicologia tomou muitas formas: é difícil calcular precisamente o número de crianças excluídas de oportunidades educacionais pelo uso indiscriminado, embora seguindo rigorosamente protocolos científicos, de testes psicológicos (PATTO, 1987); mesmo a atenção ao sofrimento no âmbito clínico padece da contradição de ajudar o indivíduo enganando-o sobre a origem de seu conflito, que inescapavelmente é socialmente mediada (CROCHIK, 2007). Olhar a história da Psicologia pelo seu lado bárbaro não implica uma defesa do niilismo ou do irracionalismo, mas consiste em escovar a história a contrapelo, pois a narrativa predominante é triunfal e afirma: hoje sabemos muito mais sobre o comportamento e a subjetividade do que há dois séculos, graças aos grandes heróis que criaram as teorias, técnicas e práticas psicológicas.

Na maior parte dos manuais a história da Psicologia é narrada do ponto de vista dos vencedores. Ao abstrair das contradições da sociedade, na qual se desenvolvem as ciências, eles acabam, voluntariamente ou não, por conceber a Psicologia como ciência europeia e norte-americana, masculina, bran$\mathrm{ca}$, desprovida de interesses políticos e alheia ao que ocorre no mundo real. Nesse os seres humanos lutam para sobreviver em meio a diferenças sociais gritantes, justificadas por preconceitos e estereótipos que procuram legitimar diversas formas de violência direta ou indireta, sutil ou brutal. Em alguns deles não há sequer referências em nota de rodapé à recepção e criação de teorias psicológicas nos países do hemisfério sul, à contribuição das mulheres ou de cientistas negros para o desenvolvimento da ciência, à inevitável mediação dos estereótipos e valores sociais na determinação do que se dispunham a estudar os medalhões da ciência Psicológica. Fica-se com a impressão de que, aos psicólogos do lado de baixo da linha do Equador, só resta esperar sempre os modelos vindos do centro do mundo, aplicando aqui sem crítica aquilo que se desenvolveu a partir de demandas e problemas outros. Ficamos lidando, para citar uma expressão bastante conhecida, com ideias fora do lugar.

O processo de autocrítica da ciência psicológica, entretanto, também conta com uma história. Sempre houve vozes dissonantes, pensadores e críticos que revelaram os aspectos sombrios dos saberes psicológicos. Em alguns 
momentos da história, a crítica é suficientemente articulada e politicamente potente para se afirmar como movimento que tende a ser hegemônico. Ao menos desde os anos 70 e 80 do século passado a Psicologia vem sendo criticada por vários autores fora do eixo dominante, procurando reconhecer que as práticas e técnicas decorrentes das teorias europeias e norte-americanas em geral objetivam processos de dominação (PATTO, 1987; CARONE, 2003; LANE; CODO, 1984).

Simultaneamente a essa proposição no campo teórico e epistemológico a categoria dos psicólogos em suas entidades representativas e profissionais abraçaram os direitos humanos como norte ético-político para seu código de ética (CFP, 2006) e passaram a avaliar as várias dimensões da prática profissional, assim como a própria memória da Psicologia brasileira, sob a perspectiva de suas relações com o campo dos direitos humanos. A questão que se coloca é: em quais sentidos dos direitos humanos seriam úteis aos psicólogos quando estão interessados em promover a emancipação?

\section{Direitos humanos: esboço de definição e gerações}

Tomaremos a expressão "direitos humanos" neste artigo representando, ao menos, três dimensões de sentidos: a) num plano legal, formal, os direitos humanos constituem um conjunto de declarações, pactos, tratados, princípios constitucionais, leis etc., que estabelecem um dos principais parâmetros legais das sociedades capitalistas modernas a partir de princípios como liberdade e igualdade, aplicados negativamente ao indivíduo e, nesse sentido estrito, com pretensão universal; b) num plano histórico e político, os direitos humanos consubstanciam anelos e ideais elaborados nas lutas de cidadãos, trabalhadores, mulheres, negros, indígenas, pessoas portadoras de deficiências, populações marginalizadas ou perseguidas, apátridas etc., que representam reivindicações de reconhecimento, não somente legal, mas também social e cultural e que, embora sejam demandas particulares desses grupos, são afirmados como valores universais para a humanidade; c) num plano filosófico, ético-político, os direitos humanos constituem valores que progressivamente ampliam tanto o alcance dos direitos como os significados de "humano", adjudicando a ele qualidades como dignidade, liberdade, igualdade etc., que passam a constituir temas acadêmicos e culturais, parte de teorias e práticas profissionais, retroagindo sobre o campo legal e das lutas sociais.

Alguns comentários sobre essa definição operacional são importantes: a) tanto a ampliação dos direitos como dos sentidos do humano são resultado das lutas sociais, o que significa que leis não produzem a realidade social, mas decorrem dos movimentos sociais ex post facto; b) nenhuma dessas dimen- 
sões isoladamente define os direitos humanos por completo e mesmo todas em conjunto ainda deixam de fora aspectos importantes do conceito como, por exemplo, sua dimensão epistemológica, igualmente plural e plena de ambiguidades (DEMBOUR, 2012); c) tomar isoladamente uma dessas dimensões como se fosse a totalidade dos direitos humanos torna a análise abstrata e ideológica, por perder de vista a dimensão histórica e social do fenômeno, junto com sua complexidade.

Não é a dimensão formal dos direitos humanos que se mostra a mais interessante a uma mirada crítica. Vistos sob as dimensões das lutas sociais e do horizonte ético-político, entretanto, os direitos humanos podem ser úteis para um diálogo sobre as possibilidades de formação crítica em Psicologia. Abordar os direitos humanos sob a óptica das lutas sociais em uma sociedade em conflito é o mote da teoria crítica dos direitos humanos defendida por Gallardo (2014). Nela os direitos humanos não são meramente despidos de sua dimensão formal, mas esta é representada para além da visão unilateralmente focada no direito, partindo essencialmente da dimensão política, isto é, das lutas sociais em torno das relações de poder e dominação. Em suas palavras:

\begin{abstract}
A concepção sócio-histórica de direitos humanos indica que o fundamento de direitos humanos está em outro mundo possível, derivado das lutas das diversas sociedades civis emergentes modernas, e na capacidade dessas lutas de conseguir a judicialização de suas demandas e a incorporação de sua sensibilidade específica ou peculiar na cultura dominante e na cotidianidade que se segue dela e potencializa sua reprodução (p. 11-12).
\end{abstract}

O olhar histórico e social revela que há um abismo entre o que se encontra na letra das leis derivadas das declarações de direitos humanos, incluindo em grande medida o que se diz sobre direitos humanos na indústria cultural, e aquilo que se faz a respeito dessas leis. Mesmo países ricos não realizam plenamente o conjunto dos direitos humanos para toda a população e em países pobres a desigualdade abissal torna inócuo o conteúdo formal dos direitos. Os mais diversos aparatos de dominação exercem seu poder não somente pela coerção direta e pelas leis, mas também pela determinação de leituras positivas sobre o que sejam o direito, o homem, a sociedade, o passado e o futuro, pressupondo um consenso abstrato sobre esses conceitos. Olhar a sociedade como campo de conflitos implica dissolver o suposto consenso prévio sobre essas determinações positivas e considerar que, enquanto sujeitos concretos, os mais diversos atores sociais sofrem e experienciam diferentemente os ideais supostamente consensuais e universais expressos nos direitos humanos. 


\section{Psicologia e direitos humanos na formação: da práxis à teoria}

Parece claro no momento dessa exposição que o ponto de partida mais útil para uma formação crítica é a práxis, ou seja, a análise dos dilemas ético-políticos envolvidos na aplicação dos saberes psicológicos tal como ocorrem em determinados âmbitos e instituições da sociedade, enfrentando as contradições, dificuldades e problemas que os profissionais encaram em sua prática. Partir da práxis não significa abandonar a teoria, nem lançar os psicólogos em formação diretamente nos locais de trabalho fazendo estágios. As relações entre teoria e práxis precisam, em si mesmas, ser tomadas dialeticamente, desfazendo o feitiço que atribui à prática, aos estágios durante a formação, por exemplo, a primazia em relação ao momento reflexivo e teórico. A premissa pragmática de que aquilo que funciona é critério de verdade - numa sociedade que opera de modo alienado, em função da reprodução ampliada do capital e às expensas de um contingente de bilhões de pessoas excluídas do usufruto das riquezas produzidas mundo afora - precisa ser radicalmente questionada.

Da mesma forma, a ansiedade por saber fazer, antes mesmo de conseguir ler adequadamente textos e pensar conceitualmente, tão comum entre professores e estudantes, revela antes o desejo de se adaptar a uma condição ruim do que verdadeira preocupação com o que é justo e adequado fazer. Não seria razoável propor uma formação eminentemente teórica, entrementes, porque as próprias teorias se encontram presas a imperativos pragmáticos. Um exemplo claro de regressão da teoria são as categorias da psicopatologia, enredada por laboratórios multinacionais em uma teia de interesses que a leva a ampliar desmedidamente o número de transtornos psíquicos, e a identificar como distúrbios psicológicos tratáveis mediante o uso de medicamentos coisas como tremores nas pernas ou "excesso" de críticas em oposição à autoridade estabelecida. Além disso, o reconhecimento tácito de que o trabalho é uma atividade fraturada e desumanizadora sob as atuais condições também justifica uma aversão à práxis que contamina a teoria com um ideal de pureza e afastamento dos problemas práticos.

Em suma, se a práxis dos profissionais das áreas "psi" encontra-se enredada em contradições, isso ocorre, primordialmente, porque a demanda fundamental que todos eles são chamados a atender é pela adaptação e ajustamento dos indivíduos a uma sociedade alienada, desigual, violenta e desumanizadora. Partir da práxis nesse contexto significa levar a sério as contradições entre essa demanda e os ideais éticos da profissão. A tarefa, portanto, é abraçar um processo de reflexão contínua sobre as aporias de uma prática orientada eticamente pela atenção ao outro, pelos valores da vida, dignidade, 
liberdade, igualdade etc., num mundo em que mesmo esses valores podem adquirir formas práticas e sentidos teóricos que desumanizam.

Aprender a pensar criticamente implica ter contato com objetos, conceitos e contextos novos, intrinsecamente amedrontadores não exatamente por serem novos, "desconhecidos", mas porque todos tivemos experiências nas quais nosso tatear intelectual foi duramente interrompido e nossa curiosidade foi mutilada ${ }^{2}$. O medo é o resultado dessas ações violentas de nossos educadores; toda criança se forma num mundo de gigantes dos quais depende radicalmente para sua sobrevivência e que nem sempre são acolhedores e amorosos. Daí o imperativo pedagógico de não esconder o medo, algo presente tanto para os educadores como para os educandos (ADORNO, 2000). Quando o medo domina o animal ele se torna tímido e impõe limites a sua capacidade de tatear e experienciar a realidade. Nos casos mais graves essa deformação leva ao ressentimento em relação a tudo o que é ainda refúgio de uma práxis não mutilada: a arte, a fantasia, a utopia, e mesmo o relaxamento físico se tornam tabus. Ao lado disso, emerge um ódio cego com relação a aquilo que, na fantasia desses sujeitos mutilados, represente alguma liberdade. O sucesso pedagógico identificado ao ajustamento das pessoas a uma sociedade alienada corresponde à formação de personalidades autoritárias.

As mudanças propostas para o ensino de graduação na universidade, nas condições emergenciais da pandemia de Covid-19, em especial as chamadas "aulas remotas", convergem com propostas e ideais de um modelo de formação universitária cuja implementação culmina no que poderíamos denominar Universidade Neoliberal. Como aponta Christian Laval (2019), embora não exista ensino sem ideais humanos, os anelos de uma formação para a cidadania e para a vida vêm sendo soterrados pelo imperativo de ajustar o sujeito ao mercado, em uma sociedade que tende para a extinção de inúmeras formas de atividade laborativa e desperdiça um enorme contingente de trabalhadores, mesmo entre os mais preparados academicamente. $O$ ideal de ajustamento ao trabalho precarizado forma os estudantes abstratamente, propondo formas de atividade cada vez mais identificadas ao "empreendedorismo", ao individualismo e à busca de interesses egoístas em detrimento de ideais sociais mais amplos (LUSA et al., 2019).

Nesse contexto emergem novos modelos de prática pedagógica, como o ensino remoto ou "híbrido", a exigência de reformulação dos projetos pedagógicos com "enxugamento" dos conteúdos e do tempo em sala de aula, a migração de aulas teóricas e estágios para ações e operações didáticas reali-

2 Confrontar, a esse respeito, o aforismo: "Sobre a Gênese da Burrice", na Dialética do Esclarecimento. (ADORNO; HORKHEIMER, 1985) 
zadas por meio de metodologias ativas, entre outras propostas, apresentadas agora como salvadoras do ensino universitário, mas que, para além do tempo de duração do necessário afastamento social para evitar contágio, tendem a se estabelecer como formas mais "eficientes" e baratas de realizar a formação. O modelo de universidade empreendedora quer adaptar o ensino aos ideais da ideologia neoliberal em flagrante contradição com os ideais de inclusão e socialização do saber (CORRÊA; CHAVES; SOUZA, 2018).

A substituição das aulas e estágios por atividades e encontros mediados por tecnologias de informação e comunicação tende a se estabelecer sem a necessária discussão sobre a justa medida em que a adoção dessas novas tecnologias seria cabível; sem parâmetros para avaliar seus resultados, sem abranger a totalidade dos estudantes - prejudicando especialmente os mais pobres -; sem que os professores tenham tempo e meios para se apropriarem das novas técnicas; sem avaliar apropriadamente que tipo de projeto pedagógico se efetiva por esses novos meios; sem saber os impactos para a saúde física e mental dos envolvidos da intensificação do trabalho decorrente; e, finalmente, mas não menos importante, sem explicitar que projeto de sociedade e universidade se tem em vista após as transformações que resultarão da pandemia e do oportunismo dos administradores da universidade. $\mathrm{O}$ incipiente projeto de democratização do ensino superior pelas políticas de cotas e expansão das vagas é varrido pela onda ultraliberal que pressupõe que a educação superior é uma mercadoria, não um direito (SGUISSARDI, 2015).

O projeto de uma universidade neoliberal já estava em curso antes da pandemia e, nela, o ajustamento às necessidades do mercado se impõe ainda mais radicalmente como um pressuposto de toda a formação que se faz na graduação e de toda pesquisa que se faz na pós-graduação. O que há tempo se considera produtivo na universidade: publicar em revistas bem avaliadas, desenvolver patentes, estabelecer convênios com empresas e produzir novas tecnologias, enquanto se intensifica o trabalho acadêmico, torna o ensino de graduação um estorvo à ascensão na carreira docente. A dedicação cuidadosa à graduação torna-se contraproducente porque toma tempo sem que resulte em reconhecimento institucional. Daí a adoção em larga escala das novas tecnologias ser vista com bons olhos por grande parte da categoria docente, iludida sobre as supostas facilidades que adviriam de seu uso. A história de todas as tecnologias desenvolvidas na era burguesa demonstra, entretanto, que o tempo que se ganha com a adoção de novas ferramentas num primeiro momento será absorvido por outras demandas, intensificando o trabalho e a exploração (ROSA, 2020).

Nesse contexto, tendo em vista a necessidade de resistir à identificação entre educação universitária e preparação para o mercado, insistimos que 
vale a pena procurar articular, na formação dos psicólogos, o campo das teorias e práticas psicológicas e os direitos humanos em uma perspectiva crítica. A categoria dos psicólogos tem produzido reflexões que geraram materiais publicados pelo Conselho Federal de Psicologia e pelos Conselhos Regionais que têm enorme potencial para iluminar aqueles dilemas e aporias que devem ser objeto de reflexão cuidadosa para que seja possível realizar na prática profissional aqueles ideais de dignidade, igualdade e liberdade que são os princípios fundamentais da ética profissional dos psicólogos ${ }^{3}$. A diversidade de temas tratados nessas publicações é significativa: a psicologia e os usuários de drogas, psicologia e assistência social, o trabalho dos psicólogos e as relações raciais, o trabalho do psicólogo em estabelecimentos penais, entre muitos outros, são todos materiais que revelam um compromisso da categoria exatamente com aquelas populações cuja dignidade e estatuto de "humanos" são continuamente desrespeitados e deslegitimados.

Na formação de psicólogos não se deve impor aos estudantes valores abstratamente, mas deve-se partir dos dilemas éticos inerentes a uma prática profissional que pretende defender e promover a dignidade a liberdade e a igualdade, num contexto em que as populações atendidas são aviltadas, violentadas e desqualificadas como seres humanos. Deve ser oportunizado ao estudante experienciar de que formas sua própria condição de sujeito se constituiu em meio a ameaças de sanções e violência na medida em que não se produzisse um imediato ajustamento à lógica do mercado. Ao revés do otimismo prático e da defesa abstrata dos direitos humanos devem ser destacadas as contradições entre a letra da lei e a realidade, de um lado, e entre as práticas habituais de ajustamento e segregação e os ideais teóricos, de outro.

A única imagem verdadeira do humano é a negativa (ADORNO, 2009), ou seja, a afirmação de identidade entre humanidade e determinadas qualidades consideradas naturais ou intrínsecas esconde, sob o manto de uma pretensa universalidade, justificativas para aniquilar aquilo que escapa a essa imagem ideal. A história das relações raciais no Brasil, tão bem criticada por Schwarcz (1993) e ironizada de forma brilhante por Lima Bareto (2013), e o modo como as primeiras publicações em Psicologia no Brasil refletem o racismo estrutural, que ainda hoje permeia nossas relações dentro e fora da universidade, são também exemplos de temas e problemas que devem ser cuidadosamente debatidos. Recuperar a história de psiquiatras negros críticos

3 Uma boa parte desses materiais está disponível nos sites do CFP (https://site.cfp.org.br/) e dos CRPs, em especial o 06, regional do Estado de São Paulo (https://www.crpsp.org/). Há, em ambos, cartilhas, livros, revistas, material iconográfico entre outros insumos que permitem identificar as reflexões feitas pela categoria na intersecção entre a prática profissional e os direitos humanos. Evidentemente, esse material pode ser muito útil para a formação se for objeto de análise crítica. 
da vertente racista dominante, como Juliano Moreira, demonstra que a luta contra o racismo na ciência brasileira não começou ontem (ODA, 2010).

O distanciamento físico, que caracteriza as aulas mediadas pelas novas tecnologias, dificulta a realização de diálogos, de encontros pessoais significativos, de manifestações espontâneas de dúvida, ponderação ou ignorância. Efetivamente, o dialogar exige preparação, disponibilidade, abertura, qualidades em declínio, como tão bem apontou Adorno (1992) no aforismo "Instituição para surdos-mudos". Torna-se mais difícil ao professor mostrar-se como ser humano, com suas fraquezas e idiossincrasias, com suas paixões e ideais, porque ele aparece agora sob o filtro da tela e o aparato exige que se respeitem as regras do seu jogo.

O ideal pedagógico em voga parece ter como modelo o jogo, os games, em que dada uma condição inicial o sujeito deve encontrar entre as alternativas já dadas pelo aparato àquela que o leva até o estágio seguinte, e assim por diante. Isso torna a todos, educadores e estudantes, apêndices do aparato, que oferece um rol prévio de alternativas já decididas (FLUSSER, 2018). O fazer sem preocupação com os fins, pseudoatividade típica dos games, se ajusta perfeitamente ao ideal de empreendedorismo que se quer impor aos estudantes. Palavras como autonomia adquirem, nesse contexto, significado positivo, não crítico, indicando que o estudante busca por si mesmo as informações e saberes de que necessita enquanto, na verdade, se sujeita à lógica ultraliberal.

Se quisermos que os ideais assumidos pela categoria em seu último código de ética (CFP, 2006) estejam presentes durante a formação, os direitos humanos não podem apenas ser apresentados positivamente. Insiste-se que os ideais colocados para a formação não devem ter caráter abstrato e que, partindo da práxis mutilada, que hoje nos é apresentada como única possibilidade, deve ser possível avançar até uma compreensão teórica e crítica, que permita um olhar transformado sobre a realidade. Há exemplos na história da psicologia brasileira em que isso ocorreu. Agora, entre os tiranos e a peste, somos novamente desafiados a utilizar nosso conhecimento e nossa sensibilidade para evitar que formas ainda piores de desumanização realizem-se no cotidiano pela atuação de profissionais formados na universidade.

\section{Referências}

ADORNO, Theodor Wiesengrund. Minima moralia: reflexões a partir da vida danificada. São Paulo: Ed. Ática, 1992.

ADORNO, Theodor Wiesengrund. Palavras e sinais: modelos críticos 2. Petró- 
polis: Ed. Vozes, 1995.

ADORNO, Theodor Wiesengrund. Educação e emancipação. São Paulo: Paz e Terra, 2000.

ADORNO, Theodor Wiesengrund. Dialética negativa. Rio de Janeiro: Jorge Zahar Ed., 2009.

ADORNO, Theodor Wiesengrund; HORKHEIMER, Max. Dialética do Esclarecimento: fragmentos filosóficos. Rio de Janeiro: Zahar Ed, 1985.

ARBEX, Daniela. Holocausto brasileiro. São Paulo: Geração Editorial, 2013.

BARRETO, Lima. Os bruzundangas. São Paulo: Martin Claret, 2013.

BENJAMIN, Walter. Obras escolhidas: magia e técnica, arte e política. São Paulo: Brasiliense, 1994.

CARONE, I. A Psicologia tem paradigmas? São Paulo: Casa do Psicólogo, 2003.

CONSELHO FEDERAL DE PSICOLOGIA. Código de Ética Profissional do Psicólogo. Brasília: 2005.

CONSELHO REGIONAL DE PSICOLOGIA. História e memória da Psicologia em SP. São Paulo: s/d. Disponível em: https://www.crpsp.org/pagina/view/197. Acesso em: 19 jun. 2020

CORRÊA, Murilo D.; CHAVES, João G. P.; SOUZA, D. P. Governar pela autonomia: universidade, inovação e capitalismo cognitivo. Eccos. Revista Científica. São Paulo, n. 47, p. 81-103, set/dez 2018.

CROCHIK, José León. Implicações políticas da psicoterapia. In: CROCHIK, J. L. et al. (org.). Teoria Crítica e formação do indivíduo. São Paulo: Casa do Psicólogo, 2007.

DEMBOUR, Marie-Bénédicte. What are Human Rignts? Four Schools of Thought. Human Rights Quarterly, v. 32, n. 1, Fevereiro, 2010, p 1-20. Disponível em: <http://muse.jhu.edu/journals/hrq/summary/v032/32.1.dembour.html $>$. Acesso em: 5 ago. 2012

FIGUEIREDO, Luís Claudio; SANTI, Pedro Luiz Ribeiro de. Psicologia: uma nova introdução. São Paulo: EDUC, 2006. 
FLUSSER, Vilém. Filosofia da caixa preta: ensaios para uma filosofia da fotografia. São Paulo: É Realizações, 2018.

FOUCAULT, Michel. Doença mental e psicologia. Rio de Janeiro: Tempo Brasileiro, 1984.

GALLARDO, Helio. Teoria Crítica: matriz e possibilidade de direitos humanos. São Paulo: Ed. Unesp. 2014.

LANE, Sílvia Tatiane M; CODO, Wanderley (org.). Psicologia Social: o homem em movimento. São Paulo: Ed. Brasiliense, 1984.

LAVAL, Christian. A Escola não é uma Empresa: neoliberalismo em ataque ao ensino público. São Paulo: Ed. Boitempo, 2019.

LUSA, Mailiz Gaibotti et al. A universidade pública em tempos de ajustes neoliberais e desmonte de direitos. Revista Katálysis. Florianópolis, v. 22, n 3, p. 536-547, set-dez, 2019.

ODA, Ana Maria Galdini Raimundo. Ordenando a babel psiquiátrica: Juliano Moreira, Afrânio Peixoto e a paranóia na nosografia de Kraepelin. História, Ciências, Saúde - Manguinhos. Rio de Janeiro, v.17, supl. 2, dez, p. 495-514, 2010.

PATTO, Maria Helena Souza. Psicologia e ideologia: uma introdução crítica à psicologia escolar. São Paulo: T. A. Queiroz Ed. 1987.

ROSA, Harmut. Aceleração: a transformação das estruturas temporais na modernidade. São Paulo: Ed. Unesp, 2019.

SCHWARCZ, Lilia Moritz. O espetáculo das raças: cientistas, instituições e questão racial no Brasil 1870-1930. São Paulo: Ed. Brasiliense, 1993.

SGUISSARDI, Valdemar. Educação Superior no Brasil: democratização ou massificação mercantil. Educação e Sociedade. Campinas, v. 36, n. 133, p. 867-889, out/dez. 2015.

TRINDADE, José Damião de Lima. História social dos direitos humanos. São Paulo: Peirópolis, 2002. 
